\title{
Predictors of Hospitalization among Children on ART in Ethiopia: a Cohort study
}

\author{
Abraham Haileamlak ${ }^{1}$, Tesfalem Hagos ${ }^{2}$, Workeabeba Abebe $^{2}$, Loko \\ Abraham $^{3}$, Henok Asefa ${ }^{4}$, Alula M. Teklu
}

\section{OPEN ACCESS}

Citation:Abraham Haileamlak, Tesfalem Hagos, Workeabeba Abebe, et al. Predictors of Hospitalization among Children on ART in Ethiopia: a Cohort study. Ethiop J Health Sci 2017;27(si1):53-62. doi: http://dx.doi.org/10.4314/ejhs.v27i1.6S Received: February 1, 2016 Accepted: August 12, 2016 Published: March 15, 2017 Copyright: () 2017 Abraham H et al. This is an open access article distributed under the terms of the Creative Commons Attribution License, which permits unrestricted use, distribution, and reproduction in any medium, provided the original author and source are credited. Funding:Center for Disease Control and Prevention (CDC) Competing Interests: The authors declare that this manuscript was approved by all authors in its form and that no competing interest exists. Affilation and Correspondence:

${ }^{1}$ Department of Pediatrics and Child Health, Jimma University

${ }^{2}$ Department of Pediatrics and Child Health, Mekelle University

${ }^{3}$ Department of Pediatrics and Child Health, Addis Ababa University

${ }^{4}$ MERQ Consultancy Services, Addis Ababa, Ethiopa

Corresponding Author: Abreham Haileamlak, E-mail: asratab@yahoo.com

\begin{abstract}
Background: Substantial progress has been made in the management of pediatric HIV infection in Ethiopia with the implementation of mother-to-child-prevention programs. Since the introduction of HAART in 2005, mortality among HIV-infected children has reduced while the rate of hospitalization was expected to rise. The purpose of this study, therefore, was to assess predictors of hospitalization in children on ART in seven university referral hospitals in Ethiopia.

Methods: A prospective cohort study design was employed on children age 0-18 years as part of a multisite observational study. ART-experienced eligible and ART-nä̈ve children with HIVIAIDS were enrolled into the Advanced Clinical Monitoring (ACM) till December 31, 2012 were included. From the database, information on hospitalization and other independent variables were extracted. Analysis was done using both SPSS for Windows version 16.0 and STATA. Descriptive analyses and modeling was done using logistic regression.

Results: Of the 405 children on ART (174 experienced, 231 naive), $86(20.7 \%)$ were hospitalized for various reasons; two children were excluded since they were hospitalized for unrelated conditions (appendicitis and burn). Fifty one (60.7\%) of the eighty four admitted children were hospitalized in the first six months of ART initiation. Of the independent variables, only the presence of opportunistic infections and duration on ART were significantly associated with hospitalization both on bi-variable and multivariable analyses (P-value $<0.05)$. As the duration on ART increased by one month, the risk of hospitalization decreased by $5.4 \%$, which is statistically significant $(P<0.001)$. Whereas the incidence (number) of OI's increased by one, the risk of being hospitalized increased by $35.2 \%(P=0.002)$. Of the individual opportunistic infections, pneumonia was found to be the only predictor of hospitalization $(P$-value $=0.002)$.

Conclusion: This study showed that nearly two-third of the hospitalization was within 6 months of initiation of ART; and presence of $\mathrm{OI}$ and duration on ART were the only predictors of hospitalization.
\end{abstract}

Key words: Hospitalization, Children, HIVIAIDS, HAART 


\section{INTRODUCTION}

The emergence of the HIV epidemic is one of the biggest public health challenges the world has ever seen in recent history. Since the confirmation of its existence HIV has affected all continents wildly spreading to children, adolescents and adults. Sub-Saharan Africa (SSA) is the epicenter of the epidemic and continues to carry the full brunt of its health and socioeconomic impact. Ethiopia is among the countries most affected by the HIV epidemic. With an estimated adult prevalence of $1.5 \%$, Ethiopia has a large number of people living with HIV; and about 1 million AIDS orphans (1).

Substantial progress has been made in the management of pediatric HIV infection worldwide, in SSA and Ethiopia with the implementation of mother-to-child-prevention programs. Early Infant diagnosis using DBS and subsequently the introduction of Highly Active Antiretroviral therapy (ART), however is lagging behind where an estimated 3.3 million children are still living with HIV, of whom 3.1 million live in sub-Saharan Africa. Although the exact prevalence of HIV in the children of Ethiopia is not known there are currently 134,586 children under 14 years living with HIV/AIDS (2). Mortality was high and premature before the introduction of HAART, reaching $35 \%$ in the first 12 months of life and $52 \%$ within 2 years of life of HIV-infected infant (3). Since 2004, however, following the introduction of ART, reductions in mortality and morbidity among HIV-infected children have been reported (4- 8).

Hospitalization represents an important outcome measure and a reliable indicator for morbidity and mortality, as well as health service utilization. The four leading causes of admission to Tikur Anbessa hospital pediatric emergency department were severe pneumonia (38.6\%), meningitis $(7.2 \%)$, sepsis $(5.6 \%)$ and heart diseases $(4.6 \%)(3,9)$. In an earlier study done in the same facility, malnutrition $(18.5 \%)$, neonatal disorders $(16.8 \%)$, diseases of the respiratory system including pneumonia $(10.6 \%)$ and infective and parasitic diseases $(9.8 \%)$ were the four major causes of admission to all the wards (4, $10)$.
Research elsewhere has shown that the rate of hospitalization is very high in children who are on HAART, particularly in the first 6 months of enrollment. For instance, in Thailand, Collins et al (2012) found hospitalization rates of 63 per 100 person years in the first 6 months on ART, declining to 10 per 100 person years after two years on HAART. In another Thai study, $(5,11)$ the incidence of hospitalization was found to be $30.7 \%$ in the first six months of life, declining to $2.0 \%$ by the third year of life. A Brazilian study $(6,12)$ found that $43.3 \%$ of children were hospitalized in the first three years of therapy. Although investigators have looked into the patterns and causes of hospitalization in children, there are little or no published studies investigating predictors of hospitalization in children on HAART.

The purpose of this study, therefore, was to assess predictors of hospitalized children on ART in seven university referral hospitals in Ethiopia.

\section{PATIENTS AND METHODS}

Background of Advanced Clinical Monitoring (ACM) of ART in Ethiopia: Seven public medical schools in Ethiopia; Addis Ababa, Defense, Gondar, Haromaya, Hawassa, Jimma, Makelle, Gondar and their affiliated hospitals agreed to establish an observational cohort study of HIV infected children and adults. The study was named the Advanced Clinical Monitoring (ACM) of ART in Ethiopia. The stakeholders were; The Federal Ministry of Health- represented by the Federal HIV/AIDS Prevention and Control Office (FHAPCO), the Ethiopian Health and Nutrition Research Institute (EHNRI) now renamed as Ethiopian Public Health Institute (EPHI) which hosted the central data and specimen repository, the Federal Science and Technology Commission (STC) the now renamed as Ministry of Science and Technology (FMoST), CDC-Ethiopia-the sponsors, and The Johns Hopkins University-Technical Support for Ethiopia on HIV/AIDS Initiative (JHU-TSEHAI) who provided technical assistance. The participating institutions signed a collaboration agreement in January 2006, and the project was formally launched in September 2006. However, enrolment of cases started in September 2009.

DOI: http://dx.doi.org/10.4314/ejhs.v27i1.6S 
An ART Register Database of all children initiated on ART since January 2005 was developed and maintained at each site. Each participating center contributed 20 randomly selected children from the ART Register database; the repository cohort consisted of 20 children per site who were ART naïve on entry to the cohort. Similar database was set for adult cases which is inclusive of children age 15-18 years. Eligibility for ART was according to Federal Ministry of Health Ethiopia ART guideline. Children were enrolled to the cohort after written informed consent (age 14-18 years) and through their guardians (below ten years). Children from ten to thirteen years old were also verbally assented.

Baseline socio demographic, clinical and laboratory data was recorded on medical forms that were standardized at all seven ACM participating sites. During the screening visit, participants had baseline medical and laboratory evaluation; while eligibility assessment for ART was made by site level physicians. Consenting patients were enrolled to the study and followed up at two and four weeks, at three months after starting of ART, and every three months thereafter. Data on adherence, ongoing clinical care, hospitalizations were recorded. Data was entered in to software called ART Information System for Ethiopia, ARTISE, at site level and then transported to the central database electronically. All identifying information was removed before transferring data. A participant was recorded as lost to follow up after she/he had missed two scheduled visits and couldn't be contacted by telephone or through her/his emergency contact. Participants could withdraw from the database at any time by informing site staff.

The national ethical clearance committee and IRBs of JHU and CDC gave approval to the study. Study design and Population: A longitudinal study design was a part of the multisite observational study. All children enrolled in the ACM pediatric database cohort and adolescents age 14-18 enrolled in the ACM adult and adolescent database cohort were included.

Sample size calculations: All the 174 ARTexperienced eligible participants and 231 ARTnaïve participants who had been enrolled into the ACM till December 31, 2012 were considered (fig. 1). Missed values were excluded from the analysis list wise.

From the database, data on hospitalization, background information at enrollment (Age, Sex, with whom the child is living), nutritional status at enrollment (Stunting, underweight, Wasting), laboratory monitoring (CD4 immune status) and clinical findings (WHO stage at enrollment) and treatment from enrollment to end of data collection (co-trimoxazole preventive therapy, Isoniazid Preventive Therapy, Duration of ART, Duration of ART before hospitalization, Regimen at enrollment) were extracted. In addition, data on reasons for hospitalization were extracted from the hospitalization abstraction sheet,

Data Analysis: Descriptive analysis was done to explain each variable selected. Modeling was done using logistic regression. As an initial step, each factor's association with hospitalization was analyzed in uni-variable logistic regression. All factors significant at $\mathrm{P}$-value $<0.05$ level was considered for the multi-variable analysis. Backward stepwise selection was used to identify independent factors associated with hospitalization in the multi-variable analysis. The data flow is shown in figure 1.

The frequency and distribution of the hospitalized cases was tabulated by principal diagnostic category as listed on the discharge report, including opportunistic infections, nonAIDS related conditions, immune reconstitution inflammatory syndrome (IRIS) and medication toxicities.

The following operational definitions were used

- Hospitalization: any child or adolescent admitted to the health facility during the course of ART due to opportunistic infections, IRIS, drug related events, other infections and non-infectious illnesses with the exception of admission for procedures or accidents irrespective of duration of hospital stay.

- Child and/or adolescent: an individual below the age of 18 years.

- Opportunistic Infection (OI): any single or multiple disease(s) that occur(s) because of weakened immune system due to HIV infection [extensive molluscum contagiosum (5\% body surface area), herpes zoster, recurrent or chronic upper respiratory tract infection (URTI), fungal nail infections, 
moderate or severe malnutrition, unexplained persistent diarrhea, unexplained persistent fever, oroesophageal candidiasis, oral hairy leukoplakia, acute necrotizing ulcerative gingivitis/ periodontitis, tuberculosis, severe pneumonia, lymphoid interstitial pneumonitis, unexplained anemia, thrombocytopenia and neutropenia, Pneumocystis carinii Pneumonitis (PCP), recurrent sever presumed bacterial infections, chronic herpes simples infection, Kaposi sarcoma, toxoplasmosis, HIV encephalopathy, CMV infection, cryptococcal meningitis, cerebral or B cell non-Hodgkin's lymphoma].

- Immune Reconstitution Inflammatory Syndrome (IRIS): is defined as evidence of favorable response to HAART with a temporal association between the initiation of HAART and onset of disease.
- Drug related events: any unfavorable/ undesirable condition with possible relationship to ARVs.

- Other infections: infections other than those listed under OI above.

- Duration of ART: the duration of treatment from initiation of ART up to end of enrolment, December 31/2012.

- Duration of ART before hospitalization- the duration of ART treatment up to hospitalization

- CD4 is classified as normal, moderate, and severe immune deficiency as per the 2009 report of the committee of infectious disease, American Academy of Pediatrics (13).

- Malnutrition: is the presence of underweight, stunting and/or wasting as defined by WHO Z score (14).

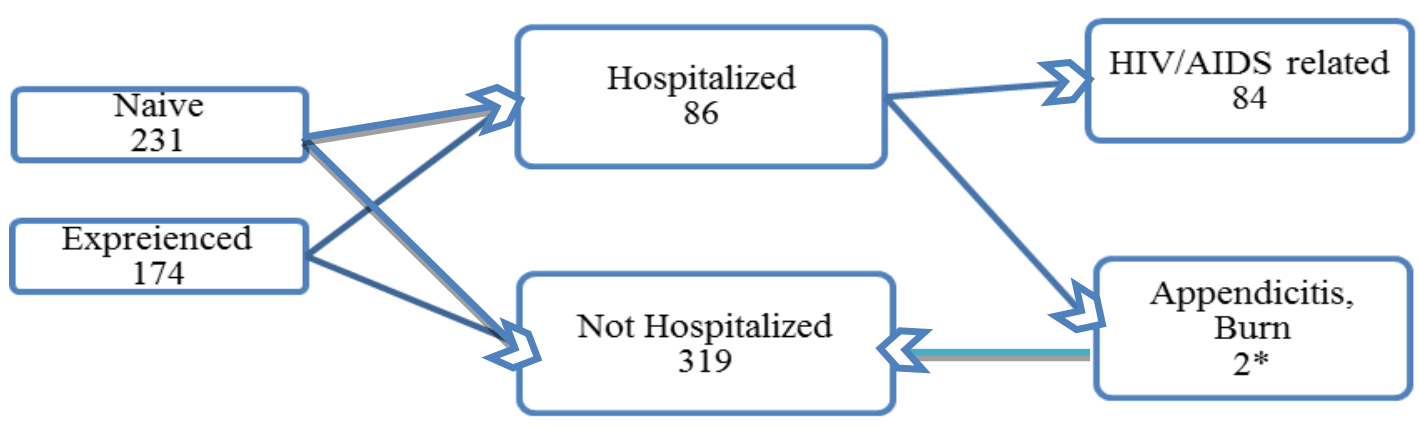

*During the analyses, the two non-HIV/AIDS related hospitalizations were considered as non-hospitalized.

Figure 1: Flow chart showing distribution among different ACM cohort groups.

\section{RESULTS}

During the cohort period, 405 children on ART, 174 from experienced and 231 from naive were enrolled. Eighty six children (20.7\%) were hospitalized for various reasons; two of them were not considered as hospitalized during our analysis since they were admitted for appendicitis and burn. Fifty one out of $84(60.7 \%)$ children hospitalized for HIV/AIDS related causes were admitted in the first six months of ART initiation (fig. 1, table 1). The 405 children were from the seven participating university hospitals. The distribution of cases among participating facilities was homogenous as shown in table 1 . 
Table 1: Frequency of cases by facility and intra-cluster homogeneity analyses among the seven facilities.

\begin{tabular}{lllll}
\hline Facility & Hospitalized & Non-Hospitalized & Odds & 95\% Conf. Interval \\
\hline Tikur Anbesa & 12 & 57 & 0.211 & $0.113-0.392$ \\
Army & 10 & 32 & 0.313 & $0.154-0.636$ \\
Gondar & 18 & 52 & 0.346 & $0.203-0.592$ \\
Jimma & 11 & 42 & 0.262 & $0.135-0.509$ \\
Mekelle & 13 & 47 & 0.277 & $0.150-0.511$ \\
Haramaya & 7 & 44 & 0.159 & $0.072-0.353$ \\
Hawassa & 13 & 47 & 0.277 & $0.150-0.511$ \\
\hline
\end{tabular}

Test of homogeneity (equal odds): $\operatorname{chi}^{2}(6)=3.35, \quad \operatorname{Pr}>\operatorname{chi}^{2}=0.7643$,

Score test for trend of odds: $\operatorname{chi}^{2}(1)=0.06, \operatorname{Pr}>\mathrm{chi}^{2}=0.8062$

Participants age was categorized based the national ART guideline age category. Accordingly, 260 (64.2) of the children were in the age group of 5-14 years with median age of 7 years. Two hundred seventy three $(84.5 \%)$ of the children were living with their parents and most of them 255(64.6\%) were WHO stage III and IV at initiation of ART. Almost all were kept on first line ART regimen; nearly $80 \%$ of them on AZT based regimen. When we see the nutritional status of these children, $86(21.2 \%)$ were underweight, 74 $(18.3 \%)$ were stunted while $65(17.8 \%)$ were wasted. Three hundred eighty $(93.8 \%)$ of the children were on Cotrimoxazole and only $2 \%$ on isoniazid preventive therapy. One hundred forty five $(45.2 \%)$ and $143(44.5 \%)$ of the children had severe and moderate immune deficiency, respectively while only $10 \%$ had normal CD4 count. One hundred seventy two $(42.5 \%)$ of the children had at least one episode of opportunistic infections. For two variables (ART Regimen type at initiation and Wasting) values were missing since height for 36 and weight for 4 children were not recorded. For one child there was no record for the ART regimen type she was on at treatment initiation (table 2).

Table 2. Background characteristics of children on ART in seven Ethiopian Referral Hospitals.

\begin{tabular}{|c|c|c|c|}
\hline Variables & Categories & Frequency & Percentage \\
\hline \multirow[t]{2}{*}{ Hospitalization } & Yes & 84 & 20.7 \\
\hline & No & 321 & 79.3 \\
\hline \multirow[t]{2}{*}{ Sex } & Male & 207 & 51.1 \\
\hline & Female & 198 & 48.9 \\
\hline Age Category in year & $\begin{array}{l}0-4 \\
5-9 \\
10-18\end{array}$ & $\begin{array}{l}117 \\
196 \\
92\end{array}$ & $\begin{array}{l}28.9 \\
48.4 \\
22.7\end{array}$ \\
\hline Child live with & $\begin{array}{l}\text { Parents } \\
\text { Others }\end{array}$ & $\begin{array}{l}273 \\
50\end{array}$ & $\begin{array}{l}84.5 \\
15.5\end{array}$ \\
\hline Baseline WHO Stage & Stage I \& II & 140 & 35.4 \\
\hline \multirow[t]{3}{*}{ ART Regimen at initiation ${ }^{*}$} & $\begin{array}{l}\text { Stage III \& IV } \\
\text { AZT or D } 4 \mathrm{~T}+3 \mathrm{TC}+\mathrm{NVP}\end{array}$ & $\begin{array}{l}255 \\
318\end{array}$ & $\begin{array}{l}64.6 \\
78.7\end{array}$ \\
\hline & $\mathrm{AZT}$ or $\mathrm{D} 4 \mathrm{~T}+3 \mathrm{TC}+\mathrm{EFV}$ & 70 & 17.3 \\
\hline & $\begin{array}{l}\text { Other } 1 \text { st line regimens } \\
\text { Second line }\end{array}$ & $\begin{array}{l}15 \\
1\end{array}$ & $\begin{array}{l}3.7 \\
0.3\end{array}$ \\
\hline Under Weight & $\begin{array}{l}\text { Yes } \\
\text { No }\end{array}$ & $\begin{array}{l}86 \\
319\end{array}$ & $\begin{array}{l}21.2 \\
78.8\end{array}$ \\
\hline Stunted & Yes & 74 & 18.3 \\
\hline
\end{tabular}

DOI: http://dx.doi.org/10.4314/ejhs.v27i1.6S 


\begin{tabular}{llll}
\hline \multirow{2}{*}{ Wasted $^{¥}$} & No & 331 & 81.7 \\
\multirow{2}{*}{ CPT } & Yes & 65 & 17.8 \\
& No & 300 & 82.2 \\
IPT & Yes & 380 & 93.8 \\
& No & 25 & 6.2 \\
CD4 count at ART start & Yes & 8 & 2.0 \\
& No & 397 & 98.0 \\
& Normal & 33 & 10.3 \\
OIs & Moderate & 143 & 44.5 \\
& Severe & 145 & 45.2 \\
\hline
\end{tabular}

${ }^{¥}$ Values do not add up 405 as some information was not captured.

In identifying the possible predictors of only showed the presence of opportunistic hospitalization from dependent variables, logistic infections and duration on ART associated with regression was done. Accordingly, of the hospitalization (table 3).

exploratory variables, using bi-variable analyses

Table 3. Association of background characteristics with hospitalization using bi-variable logistic regression

\begin{tabular}{|c|c|c|c|c|c|c|c|}
\hline \multirow[b]{2}{*}{ Variables } & \multirow[b]{2}{*}{ Categories } & \multicolumn{2}{|c|}{ Hospitalization } & \multirow[b]{2}{*}{ COR } & & & \multirow[b]{2}{*}{ P-value } \\
\hline & & $\begin{array}{l}\text { Yes } \\
\mathbf{N}(\%)\end{array}$ & $\begin{array}{r}\text { No } \\
\mathbf{N}(\%) \\
\end{array}$ & & \multicolumn{2}{|c|}{$95 \% \mathrm{CI}$} & \\
\hline \multirow[t]{2}{*}{ Sex } & Female & $36(18.2)$ & $162(81.8)$ & 1 & & & \\
\hline & Male & $48(23.2)$ & $159(76.8)$ & 1.36 & 0.84 & 2.21 & 0.215 \\
\hline \multirow[t]{3}{*}{ Age Category } & $<5$ years & $28(23.9)$ & $89(76.1)$ & 1 & & & \\
\hline & $5-9$ years & $40(20.4)$ & $156(79.6)$ & 0.82 & 0.47 & 1.41 & 0.465 \\
\hline & $10-18$ years & $16(17.4)$ & $76(82.6)$ & 0.67 & 0.34 & 1.33 & 0.251 \\
\hline \multirow[t]{2}{*}{ Child live with } & Parents & $60(22)$ & 213(78) & 1.28 & 0.59 & 2.79 & 0.529 \\
\hline & Others & $9(18)$ & $41(82)$ & 1 & & & \\
\hline \multirow{3}{*}{$\begin{array}{l}\text { Baseline WHO } \\
\text { Stage }\end{array}$} & Stage I \& II & $23(16.4)$ & 117(83.6) & 0.65 & 0.38 & 1.11 & 0.117 \\
\hline & Stage III \& IV & $59(23.1)$ & $196(76.9)$ & 1 & & & \\
\hline & $\mathrm{AZT}$ or $\mathrm{D} 4 \mathrm{~T}+3 \mathrm{TC}+\mathrm{NVP}$ & $66(20.8)$ & $252(79.2)$ & 1 & & & \\
\hline \multirow{2}{*}{$\begin{array}{l}\text { ART Regimen at } \\
\text { initiation }\end{array}$} & $\mathrm{AZT}$ or $\mathrm{D} 4 \mathrm{~T}+3 \mathrm{TC}+\mathrm{EFV}$ & $14(20)$ & $56(80)$ & 0.96 & 0.5 & 1.82 & 0.888 \\
\hline & Other 1 st line regimens & $4(26.7)$ & $11(73.3)$ & 1.39 & 0.43 & 4.5 & 0.584 \\
\hline \multirow[t]{2}{*}{ Under Weight } & Yes & $19(22.1)$ & $67(77.9)$ & 1.11 & 0.62 & 1.98 & 0.728 \\
\hline & No & $65(20.4)$ & 254(79.6) & 1 & & & \\
\hline \multirow[t]{2}{*}{ Stunted } & Yes & $18(24.3)$ & $56(75.7)$ & 1.29 & 0.71 & 2.34 & 0.401 \\
\hline & No & $66(19.9)$ & $265(80.1)$ & 1 & & & \\
\hline \multirow[t]{2}{*}{ Wasted } & Yes & $18(27.7)$ & $47(72.3)$ & 1.71 & 0.92 & 3.16 & 0.09 \\
\hline & No & $55(18.3)$ & $245(81.7)$ & 1 & & & \\
\hline \multirow[t]{2}{*}{ CPT } & Yes & $81(21.3)$ & $299(78.7)$ & 1 & & & \\
\hline & No & $3(12)$ & $22(88)$ & 0.5 & 0.15 & 1.72 & 0.274 \\
\hline INH & Yes & $1(12.5)$ & $7(87.5)$ & 1 & & & \\
\hline
\end{tabular}

DOI: http://dx.doi.org/10.4314/ejhs.v27i1.6S 


\begin{tabular}{llcccccc}
\multicolumn{1}{c}{} & No & $83(20.9)$ & $314(79.1)$ & 1.85 & 0.23 & 15.2 & 0.567 \\
CD4 Category & Severe & $25(17.2)$ & $120(82.8)$ & 1 & & & \\
& Moderate & $27(18.9)$ & $116(81.1)$ & 1.12 & 0.61 & 2.04 & 0.718 \\
& Normal & $8(24.2)$ & $25(75.8)$ & 1.54 & 0.62 & 3.79 & 0.353 \\
OI & Yes & $44(25.6)$ & $128(74.4)$ & 1.66 & 1.02 & 2.67 & 0.04 \\
& No & $40(17.2)$ & $193(82.8)$ & 1 & & & \\
Number of OI's & & & & 1.23 & 1.06 & 1.4 & $\mathbf{0 . 0 0 6}$ \\
Duration on ART & & & & 0.93 & 0.91 & 0.95 & $<\mathbf{0 . 0 0 1}$ \\
\hline
\end{tabular}

The two variables- OIs and duration on ART remained to be strong predictors of hospitalization on multivariable analyses. As the duration on ART increased by one month, the risk of hospitalization decreased by $5.4 \%$ which is statistically significant $(\mathrm{P}<0.001)$. However, when the incidence (number) of OI's increased by one, the risk of being hospitalized increased by $35.2 \%, \mathrm{P}=0.002$ (table 4).

Table 4. Predictors of hospitalization among children on ART in Ethiopia

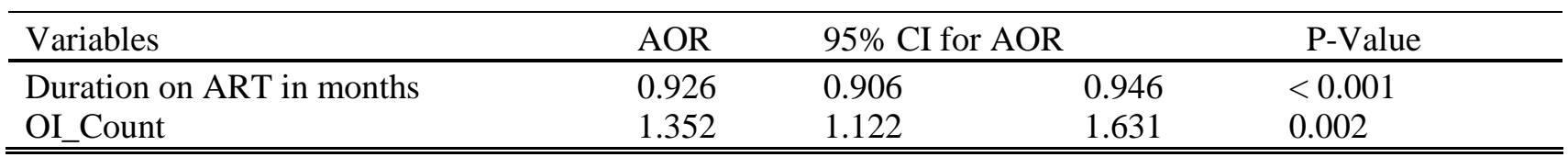

The study tried to identify which opportunistic infections could predict hospitalization. In doing so the commonly seen opportunistic infections were tallied and bi-variable regression done for hospitalization against the presence or presence of individual opportunistic infection and pneumonia was found to be the only predictor of hospitalization $(\mathrm{P}$-value $=0.002)($ table 5$)$.

Table 5. Opportunistic infections versus hospitalization among children on ART in Ethiopia

\begin{tabular}{llccc}
\hline & & \multicolumn{2}{c}{ Hospitalization } & \\
\cline { 3 - 4 } OI Type & & Yes & No & \multirow{2}{*}{ P-Value } \\
\hline Pneumonia & No & $52(17.2)$ & $251(82.8)$ & \multirow{2}{*}{0.002} \\
Oral Candidiasis & Yes & $32(31.4)$ & $70(68.6)$ & \\
& No & $78(20.6)$ & $301(79.4)$ & \multirow{2}{*}{0.761} \\
Malnutrition & Yes & $6(23.1)$ & $20(76.9)$ & \\
& No & $71(20.1)$ & $283(79.9)$ & \multirow{2}{*}{0.371} \\
Other OI & Yes & $13(25.5)$ & $38(74.5)$ & \\
& No & $72(20.9)$ & $272(79.1)$ & 0.823 \\
\hline \hline
\end{tabular}

Although there were over eleven disease categories as reasons for hospitalization, only three - acute respiratory infections, malnutrition and neurological problems accounted for 33 $(38.4 \%), 9(10.5 \%)$ and $7(8.2 \%)$, respectively (Fig 2).

DOI: http://dx.doi.org/10.4314/ejhs.v27i1.6S 


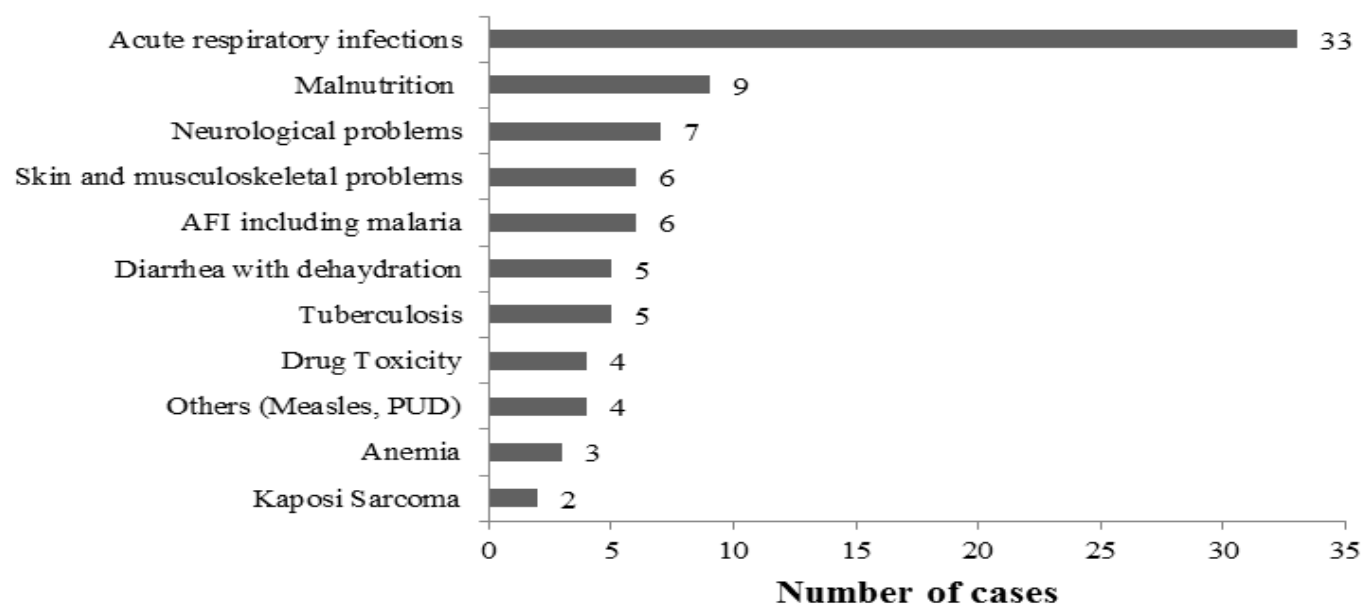

Figure 2: Frequency distribution of causes of hospitalization

\section{DISCUSSION}

This Prospective Cohort study aimed to identify the predictors of hospitalization among children in Ethiopia. Eighty four children $(20.7 \%)$ out of the total 405 in the study were hospitalized at least once for various reasons. The result is similar to a study done in Thailand where $35 \%$ children were hospitalized (5). However, this study may not be representative to all children with HIV in Ethiopia as many others may be hospitalized in district or regional hospitals.

The majority of the children $(60.7 \%)$ were admitted within the first 24 weeks of HAART initiation, which is not different from other similar studies. The median time of ART among those hospitalized in West Africa was 9.8 months (15). The first 6 months of treatment is characterized by high mortality of hospitalization until the patient gets stabilized (5).

The mean age at HAART initiation in our study population was 7 years which is similar to the study done in Thailand where it was 7.6 years (5). This finding is a bit late than the one reported in West Africa where the HAART initiation age was 3 years (15). While HIV in children is known for its fast progression, the mortality is quiet high and if not treated timely.This study finding indicates that there has been delay in diagnosing and initiating HAART. The WHO reports that without treatment, $50 \%$ of children would die before their $2^{\text {nd }}$ birth day and if delayed until 5 years, $75 \%$ of them would die (16); emphasizing the need for early infant diagnosis and treatment.

Malnutrition in the form of underweight, stunting or wasting based on the WHO Z-score was common among those children. Eighty six children (21.2\%) were underweight, $18.3 \%$ stunted and $17.8 \%$ wasted. Malnutrition is considered to be the most common manifestation of HIV infected children in developing countries $(17,18)$. A study that dealt with clinical profile of hospitalized HIV -infected children in Bangladesh found that for children below 5 years of age, the mean Weight for Age Z-score (WAZ) was -2.1 and Height for Age Z-score (HAZ) HAZ was -2.9 while for older than 5 years of age the mean BMI was 12.6 (19).

More than half 44(52.4\%) of those hospitalized had at least one episode of opportunistic infection (OI), while only $128(39.9 \%)$ of those non-hospitalized had OI. Presence of OI was found to be associated with hospitalization with P-value of $<0.05$ using both bi-variable and multi-variable analysis. A study done among children and young adults in United States of America HIV clinics revealed that CD4 count and HIV-1RNA were strongly associated with hospitalization (20). We don't have data on viral load in most of our cases and the CD4 count (though few missing) was not found to be significantly associated with hospitalization. Presence of OI could be a proxy indicator of low CD4. 
The other variable which was associated with hospitalization was duration on ART-the lesser the duration the higher the chance of getting hospitalized. This indicated that children were initiated late after they developed OIs and soon after treatment initiation got hospitalized either due to the OIs or IRIS. Care interventions aiming at identifying the earliest possible HIV-infected infants and treating them according to current guidelines would drastically reduce cost of HIV care including costs related to hospitalization (15). Studies in Thailand and South Africa have shown that early ART initiation incur lower in patient care costs $(21,22)$.

The major causes of hospitalization were pneumonia 33(38.1), malnutrition $9(10.5 \%)$ and neurological conditions like seizure and focal neurological deficits. Furthermore, this study also revealed pneumonia to be the single predicator of hospitalizations among OIs. Other studies also

\section{ACKNOWLEDGMENT}

The Research has been supported by the President's Emergency Plan for AIDS Relief (PEPFAR) through the Centers for Disease Control and Prevention (CDC) under the terms of Cooperative Agreement with Johns Hopkins School of Public health number PS000858.

\section{REFERENCES}

1. Federal Democratic Republic of Ethiopia Country Progress Report HIV/AIDS Response, 2012, democratic republic of Ethiopia

2. Guidelines for Pediatric HIV/AIDS Care and Treatment in Ethiopia, 2007

3. Newell M-L, Coovadia H, Cortina-Borja M, Rollins N, Gaillard P, Dabis F. Mortality of infected and uninfected infants born to HIV infected mothers in Africa: a pooled analysis. Lancet, 2004;364(9441):1236-43.

4. Arrive' E, Kyabayinze DJ, Marquis B, Tumwesigye N, Kieffer M-P, Azondekon A, et al. Cohort profile: the paediatric antiretroviral treatment programs in lowerincome countries (KIDS-ART-LINC) Collaboration. Int $J$ Epidemiol, 2008;37(3):474-80. showed that pneumonia to be the leading cause of hospitalizations $(5,15)$.

In conclusion, this cohort study showed that HAART initiation age was late, presence of OI and duration on ART were the only predictors of hospitalization and pneumonia was the leading cause of hospitalization. This study might not be generalized to all children enrolled in ART in Ethiopia such as those following at primary level health care as it is done in Tertiary teaching hospitals.

\section{DISCLAIMER}

The findings and conclusions in this report are those of the author(s) and do not necessarily represent the official position of the Centers for Disease Control and Prevention.

5. Ciaranello AL, Chang Y, Margulis AV, Bernstein A, Bassett IV, Losina E, et al. Effectiveness of pediatric antiretroviral therapy in resource-limited settings: systematic review and meta-analysis. Clin Infect Dis, 2009;49(12):1915-27.

6. Collins IJ, Jourdain G, Hansudewechakul R, Kanjanavanit $\mathrm{S}$, Hongsiriwon $\mathrm{S}$, Ngampiyasakul C, et al. Long-term survival of HIV-infected children receiving antiretroviral therapy in Thailand: a 5-year observational cohort study. Clin Infect Dis, 2010;51(12):1449-57.

7. Edmonds A, Yotebieng $\mathrm{M}$, Lusiama J, Matumona Y, Kitetele F, Napravnik S, et al. The effect of highly active antiretroviral therapy on the survival of HIV-infected children in a resource-deprived setting: a cohort study. PLoS Med, 2011;8(6):e100104.

8. Sutcliffe CG, van Dijk JH, Bolton C, Persaud D, Moss WJ. Effectiveness of antiretroviral therapy among HIV-infected children in subSaharan Africa. Lancet Infect Dis, 2008;8(8):477-89.

9. Dagnew Muluneh, Damte Shimelis, Daniel Benti. Analysis of admissions to pediatric emergency ward of Tikur Anbessa Hospital in Addis Ababa, Ethiopia. Ethiop J Health Dev, 2007;21(1):48-50. 
10. Tafesse B. Analysis of admission of theEthioSwedish pediatric clinic $(1970$ - 1971).EM J, 1973; 11:3-11.

11. Thanyawee Puthanakit, Linda Aurpibul, Peninnah Oberdorfer, Noppadon Akarathum, Suparat Kanjananit, PornphunWannarit, Thira Sirisanthana, Virat Sirisanthana. Hospitalization and Mortality among HIVInfected Children after Receiving Highly Active Antiretroviral Therapy. Clinical Infectious Diseases, 2007; 44:599-604.

12. Diniz LM, Maia MM, Camargos LS, Amaral LC, Goulart EM, Pinto JA, Impact of HAART on growth and hospitalization rates among HIV-infected children. J Pediatr (Rio J), 2011; 87(2):131-7.doi:10.2223/JPED.2064. Epub 2011 Mar 16.

13. The 2009 report of the committee of infectious disease, American Academy of Pediatrics.

14. World Health Organization. WHO Global Database on Child Growth and Malnutrition.http://www.who.int/maternal _child_adolescent/en/ accessed on July 10, 2014.

15. Fatoumata Dicko, Sophie Desmonde, Sikiratou Koumakpai, He' le`ne Dior-Mbodj, Fla Koue'ta, Novisi Baeta,Niaboula Kone, Jocelyn Akakpo, Haby Signate Sy, Diarra Ye, Lorna Renner, Charlotte Lewden and Vale'riane Leroy, for the Pediatric IeDEA West Africa Working Group*

Reasons for hospitalization in HIV-infected children in West Africa. Journal of the International AIDS Society, 2013;17:18818.

16. Violari A, et al, Early antiretroviral therapy and mortality among HIV-infected infants. $N$ Engl J Med, 2008.359 (21): 2233-44.
17. Lodha R, Upadhyay A, Kapoor V, Kabra SK. Clinical Profile and natural history of children with HIV infection. Indian J Med Res, 2009;129:42-9.

18. Rajasekaran S, Jeyaseelan L, Raja K, Ravichandran N, Demographic and clinical profile of HIV infected children accessing care at Tambaram, Chennai, India. Indian J Med Res, 2009;129:42-9.

19. Lubaba Shahrin, Daniel T.Leung, Nashaba Martin, et al. Clinical Profile of hospitalized HIV-infected children in Bangladesh, a lowHIV prevalence country.

20. Stephen A. Berry, Kelly A. Gebo, MD, Richard M. Rutstein, Keri N. Althoff, P. Todd Korthuis, Aditya H. Gaur, MD, Stephen A. Spector, Robert Warford, CRNP, Baligh R. Yehia, and Allison L. Agwu, MD, for the HIV Research Network. Trends in Hospitalizations Among Children and Young Adults with Perinatally Acquired HIV

21. Collins IJ, Cairns J, Jourdain G, Fregonese F, Nantarukchaikul M, Lertpienthum N, Wannarit P, Attavinijtrakarn P, Layangool P, Le Coeur S, Lallemant M; Program for HIV Prevention and Treatment (PHPT) study team, Hospitalization trends, costs, and risk factors in HIV-infected children on antiretroviral therapy. AIDS, 2012 Sep 24; 26(15):1943-52.

22. Leisegang R, Cleary S, Hisiop M, Davidse A, Regensberg L, Little F, et al. Early and late direct costs in a Southern African antiretroviral treatment programme: a retrospective cohort analysis. Plos medicine, 2009;6(12);e1000189. 